\title{
THE ROLE OF THE ENDOCRINE GLANDS IN KETOSIS. II. KETONEMIA FOLLOWING INSULIN HYPOGLYCEMIA *
}

\author{
By THOMAS T. AMATRUDA, Jr., JOAN W. CHASE and FRANK L. ENGEL \\ (From the Departments of Medicine and Physiology and the Division of Endocrinology, Duke \\ University Medical Center, Durham, N. C., the Veterans Administration Hospital, \\ West Haven, Conn., and the Department of Medicine, Yale University \\ School of Medicine, New Haven, Conn.)
}

(Submitted for publication October 16, 1961 ; accepted November 13, 1961)

The pituitary, adrenal, and other endocrine glands are generally assumed to play a critical, or even indispensable role in the development of ketosis. However, a previous study demonstrated that in the rat neither the hypophysis nor the adrenal was essential for ketosis during a prolonged fast (1), although they did influence the magnitude of the ketonemia and recovery therefrom as the fast was prolonged.

In the present study we investigated the ability of the endocrine-deficient rat to develop ketosis acutely in response to insulin-induced hypoglycemia. In these studies "ketosis" is considered as any state "in which the liver produces acetoacetic and $\beta$-hydroxybutyric acids more rapidly than they can be burned by the tissues" (2). Quantitatively it may vary from the minimal but physiologically important elevations in fasting to the profound pathological ketosis of diabetic acidosis. These studies were concerned with physiological rather than pathological ketosis, although in many respects the two differ only in degree. The sequence of events, hypoglycemia followed by ketosis, simulates the metabolic pattern of prolonged fasting telescoped into a period of a few hours. The same pattern occurs in an exag-

\footnotetext{
* Supported by research grants from the American Cancer Society; the National Institute of Arthritis and Metabolic Diseases (A-1324); and by Contract no. DA49-007-MD-134 from the Medical Research and Development Division, Office of the Surgeon General, Department of the Army. Some of the material presented here has appeared in abstract form: Clin. Res. Proc. 1956, 4, 124 ; J. clin. Endocr. 1956, 16, 983.

$\dagger$ Alfred Stengel Research Fellow of the American College of Physicians, 1955-56; Fellow in Cancer Research of the American Cancer Society, 1956-57; Present address: VA Hospital, West Haven, and Dept. of Medicine, Yale University School of Medicine, New Haven, Conn.
}

gerated fashion in patients with diabetes following excessive doses of insulin (3).

The data obtained demonstrate that ketosis can develop in the rat in the absence of the pituitary or adrenal glands, and in the absence of both. Influences of the thyroid hormone, endogenous insulin, glucagon, and epinephrine upon the production and correction of insulin hypoglycemia ketosis were also studied.

\section{MATERIALS AND METHODS}

Male Vanderbilt rats weighing 200 to $300 \mathrm{~g}$ were used in most experiments. Individually caged in an $80^{\circ} \mathrm{F}$ room, they received water and Purina dog chow, ground or pellets, ad libitum. Hypophysectomized rats and their intact controls were of the Sprague-Dawley strain. ${ }^{1}$ Adrenalectomized and hypophysectomized-adrenalectomized rats received deoxycorticosterone acetate (DCA), $0.5 \mathrm{mg}$ subcutaneously daily. The weight loss after adrenalectomy was regained before the animals were used, and completeness of adrenalectomy and absence of accessory adrenal tissue were confirmed by autopsy. Hypophysectomized rats were studied either "early" (11 to 58 days) or "late" (more than 77 days after hypophysectomy). Completeness of hypophysectomy was assumed from failure of the rats to grow, testicular atrophy, changes in body hair, decreased spontaneous motor activity, exquisite sensitivity to insulin and adrenocortical atrophy. This assumption was verified by histological examination of the sella turcica and para sellar regions in the final group of rats used. A solution of L-triiodothyronine was prepared as outlined by Heming and Holtkamp (4). Epinephrine (Parke, Davis), glucagon (Lilly), and solutions of "regular" or glucagonfree insulin in 0.9 per cent saline were employed. In addition, crystalline glucagon was treated with cysteine to inactivate any residual insulin.

Between 8 and 9 a.m. blood was obtained from the tail of unanesthetized rats fasted for 24 hours, and insulin was injected intraperitoneally. They were placed in a cabinet maintained at $33^{\circ} \mathrm{C}$ and additional blood was obtained at 2,4, and 6 hours for determination of glucose

\footnotetext{
${ }^{1}$ The Endocrine Laboratories, Madison, Wis.
} 
KETONEMIA FOLLOWING INSULIN HYPOGLYCEMIA

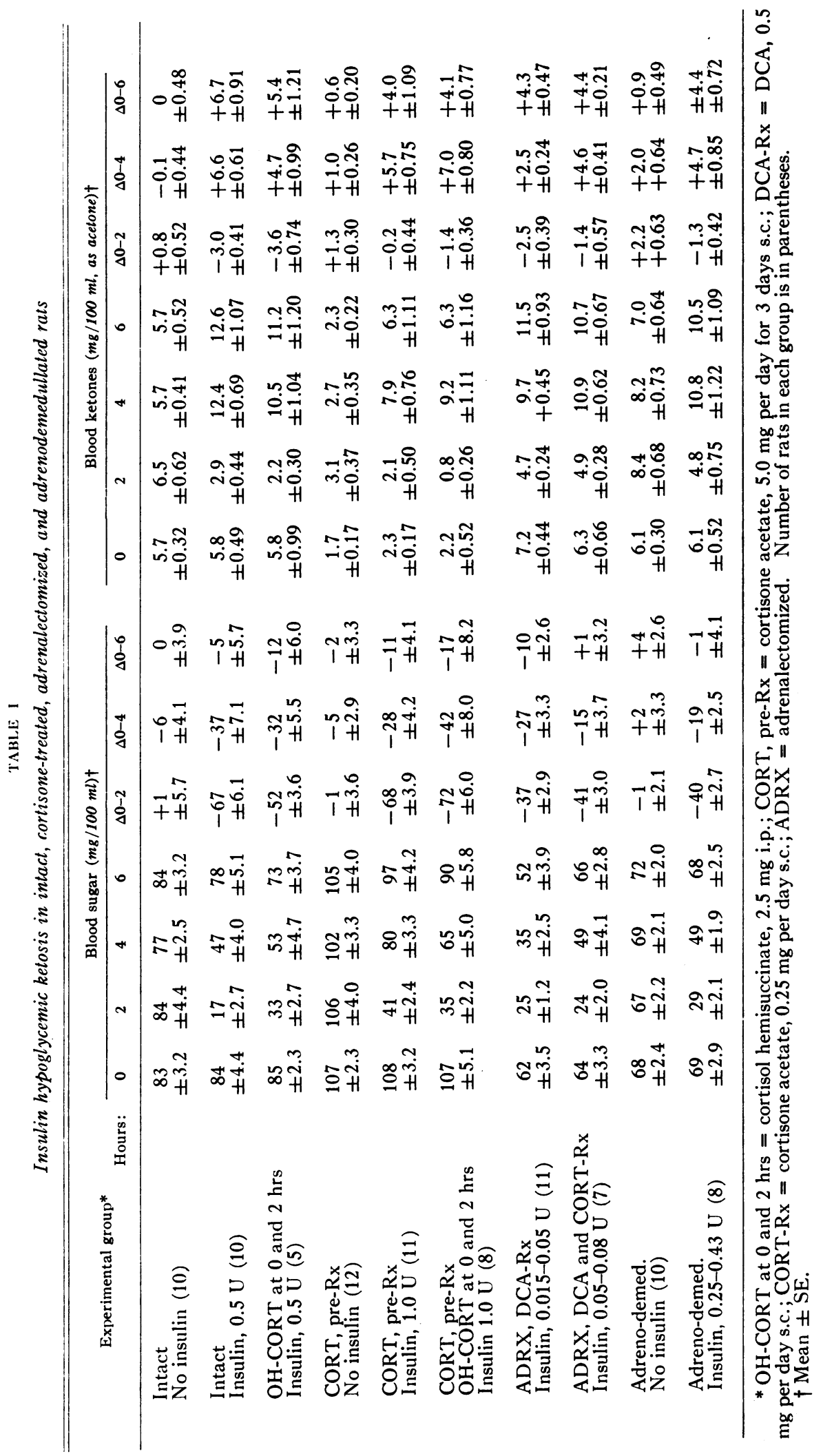


(5) and ketone bodies (6). Rats which developed shock or convulsions were excluded, since impairment of the circulation supresses ketosis (7). Administration of other hormones or deviations from the usual protocol are noted below. In some instances liver obtained from rats anesthetized with sodium pentobarbital was analyzed for glycogen (8).

\section{RESULTS}

The data in Table I were obtained to assess the role of the adrenal in ketosis following insulin hypoglycemia. In intact rats ketonemia and glycemia remained stable during a 6-hour control period. In contrast, ketone levels initially fell 2 hours after injection of insulin followed by a rise to levels over $12 \mathrm{mg}$ per $100 \mathrm{ml}$ at 4 and 6 hours, an increment of $6.6 \mathrm{mg}$ per $100 \mathrm{ml}$ above the fasting ketonemia.

Cortisone pretreatment suppresses ketosis during fasting and cold stress in rats (9), but does not prevent the increase in ketonemia and net splanchnic ketone body production following insulin hypoglycemia in either man (10) or the rat (Table I). Despite several different steroid regimens, the increments in ketonemia at 4 and 6 hours were of the same order as in normals. Since cortisone pretreatment effectively suppressed fasting ketosis, the absolute levels achieved at 4 and 6 hours were lower than in controls. A larger dose of insulin was necessary to produce hypoglycemia in the cortisone-pretreated rats. During a prolonged fast in normal rats, maximal ketonemia occurs in 48 hours and then declines (1). Adrenal glucocorticoids are essential for the decline. However, cortisone pretreatment did not accelerate recovery from insulin hypoglycemic ketosis. The increments in ketonemia above the fasting level 8 hours after insulin in 9 controls $(+3.0 \pm 0.41 \mathrm{mg}$ per $100 \mathrm{ml})$ and in 12 cortisone-pretreated rats $(+2.8 \pm 0.35)$ did not differ and represented a decline from those present at 4 hours $(+6.0 \pm 0.70$ and $+7.3 \pm 0.66$, respectively).

A possible explanation for the ability of cortisone pretreatment to suppress the ketosis of fasting while it fails to suppress the ketosis following insulin hypoglycemia became apparent when the glycogen content of the liver was determined. In 12 cortisone-pretreated rats, fasted for 24 hours and bled at $0,2,4$, and 6 hours, the liver glycogen level at 6 hours was $3.62 \pm 0.41 \mathrm{~g}$ per $100 \mathrm{ml}$ (mean $\pm \mathrm{SE})$. This contrasted sharply with a level of only $0.65 \pm 0.17 \mathrm{~g}$ per $100 \mathrm{ml}$ in 5 similarly pretreated rats which received insulin ( $p$ $<0.01$ ).

The effects of adrenalectomy and adrenodemedullation upon ketosis are also tabulated in Table I. Rats adrenalectomized 5 to 13 days earlier received DCA to combat circulatory failure, which suppresses ketosis (7). Without such protection adrenalectomized rats did not develop ketosis readily during fasting 11). The adrenalectomized rats exhibited fasting hypoglycemia and a brisk response to the small dose of insulin used. The initial blood ketone level was slightly but significantly higher $(\mathrm{p}<0.05)$ in the adrenalectomized group, as previously reported (11). In response to insulin hypoglycemia, small but statistically significant increases in ketonemia occurred at 4 and 6 hours. However, the response, which was less than in the controls $(p<0.01$ and $\mathrm{p}<0.05$ ), is difficult to interpret since some degree of circulatory insufficiency was present. Adrenalectomized rats do not tolerate hypoglycemia well even when maintained on DCA. The addition of a constant dose of cortisone acetate (0.25 $\mathrm{mg}$ per day) improved their tolerance to hypoglycemia and augmented the increment in ketonemia at 4 hours.

Adrenodemedullated rats studied 4 to 5 weeks postoperatively had lower fasting blood sugar levels than intact controls. Since they recovered from hypoglycemia promptly despite a large dose of insulin, their adrenal cortical function was reasonably intact. The absence of a hyperglycemic response to adrenaline secretion consequent to handling might explain the subnormal glycemia. The ketone response to hypoglycemia was comparable to the normal, indicating the dispensability of the adrenal medulla in insulin hypoglycemic ketosis.

The roles of the hypophysis and hypophyseal target gland interrelationships in insulin hypoglycemic ketosis were investigated by experiments recorded in Table II. Hypophysectomized rats could tolerate only extremely minute doses of insulin. Doses greater than $0.037 \mathrm{U}$ caused hypoglycemic shock, convulsions, and death. Since the hypophysectomized rats were of the SpragueDawley strain, additional controls were used. They exhibited less ketonemia in response to in- 


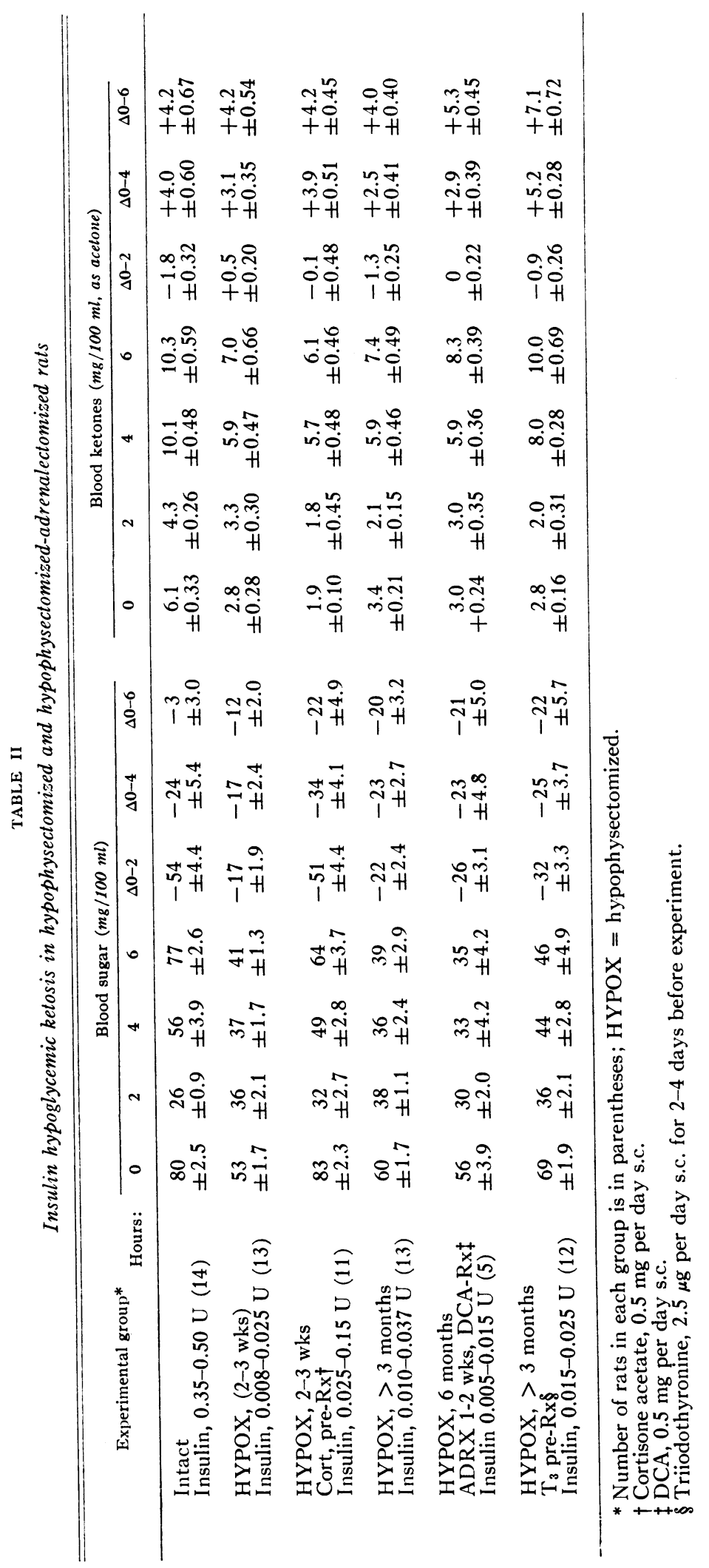


sulin hypoglycemia than did Vanderbilt strain rats. Rats hypophysectomized 2 to 3 weeks earlier exhibited a subnormal level of ketonemia after a 24-hour fast (1). However, a rise in blood ketones occurred 4 and 6 hours after a minute dose of insulin with the increments of rise ( $\Delta 0$ to $4, \Delta 0$ to 6 ) comparable to those of intact rats. When hypophysectomized rats were pretreated with $0.5 \mathrm{mg}$ of cortisone acetate daily, the low fasting blood glucose was restored to normal. Fasting ketonia remained subnormal, but the increases in blood ketones at 4 and 6 hours again did not differ from the controls. Interpretation of these data is difficult since the dose of cortisone used may have been large enough to be suppressive rather than "permissive."

To insure atrophy of the endocrine target glands, the experiment was repeated with rats hypophysectomized for more than 3 months. Although such rats develop more ketosis during a prolonged fast than do recently hypophysectomized ones (1), the response to insulin hypoglycemia was similar in both groups. Although the absolute levels of ketonemia were less than in intact rats, the increments of rise at 4 and 6 hours were not significantly different $(p<0.10$ $>0.05$ at 4 hours). Furthermore, when hypophysectomized-adrenalectomized rats maintained on DCA were tested, the ketonemic response to insulin hypoglycemia was still comparable to that of intact animals.

The effect of triiodothyronine was studied, since thyroxine restores the subnormal rate of ketogenesis of surviving liver slices from hypophysectomized rats (12). Although fasting ketonemia was unchanged, a significantly greater ketonemic response occurred at 4 and 6 hours ( $\mathrm{p}<0.01$ compared to hypophysectomized controls) and at 6 hours the degree of rise, $+7.1 \mathrm{mg}$ per $100 \mathrm{ml}$, was greater than that of both the intact and hypophysectomized controls ( $\mathrm{p}$ $<0.01$ ).

All of the preceding data were obtained while employing "regular" insulin which contains glucagon. Therefore, glucagon-free insulin was used in additional experiments on intact rats. There was no significant difference in response to the two types of insulin between the absolute levels or increments of change of either glycemia or ketonemia. Those data have been omitted to conserve space.

Neither the adenohypophysis, the adrenal medulla, nor glucocorticoids of the adrenal cortex seemed essential for insulin hypoglycemic ketosis. Since hypoglycemia suppresses endogenous insulin secretion $(13,14)$ and stimulates secretion of glucagon (15), which has been reported to affect ketosis $(16,17)$, these factors were investigated (Table III).

Glucagon-free insulin was used to induce ketosis in intact rats; then the effects of various test materials were evaluated by injecting them intraperitoneally at 4 hours and obtaining further blood samples at 5 and 6 hours. Glucose, when tested, was injected in small divided doses at 4 and 4.5 hours to avoid sudden hyperglycemia which might trigger secretion of endogenous insulin. Rats receiving insulin or glucagon at 4 hours received saline at 4.5 hours and a control group received only saline at 4 and 4.5 hours after insulin. Comparable degrees of hypoglycemia at 2 hours and ketonemia at 4 hours were obtained in all groups. There was no significant change in ketonemia at 5 or 6 hours in the saline control group. Administration of glucagon (Lilly, lot no. P-60382, said to contain less than $0.05 \mathrm{U}$ insulin per $\mathrm{ml}$ ) resulted in a significant decline in ketonemia at 5 and 6 hours $(p<0.01)$. However, crystalline glucagon, treated with cysteine to inactivate any residual insulin, no longer caused a decline at 5 hours. A significant fall in ketonemia did occur at 6 hours but the rise in blood sugar to $103 \mathrm{mg}$ per $100 \mathrm{ml}$ probably triggered endogenous insulin secretion. To verify that all residual insulin had been inactivated, a rough bioassay for insulin was carried out in 24hour-fasted hypophysectomized-adrenalectomized rats which, as demonstrated earlier, are exquisitely sensitive to insulin. When $0.005 \mathrm{U}$ of insulin in saline was injected, the blood sugar fell from a mean of $53 \mathrm{mg}$ per $100 \mathrm{ml}$ to $34 \mathrm{mg}$ per $100 \mathrm{ml}$ in 1 hour, and a small but statistically significant fall in blood ketones occurred $(-0.9$ $\pm 0.24 \mathrm{mg}$ per $100 \mathrm{ml} ; \mathrm{p}<0.01)$. The actual dose of insulin injected was probably less than $0.005 \mathrm{U}$, since a protein-containing diluent is necessary to prevent adherence of insulin to the syringe (18). When $0.55 \mathrm{mg}$ of the treated glucagon was administered to 4 of the rats, keto- 


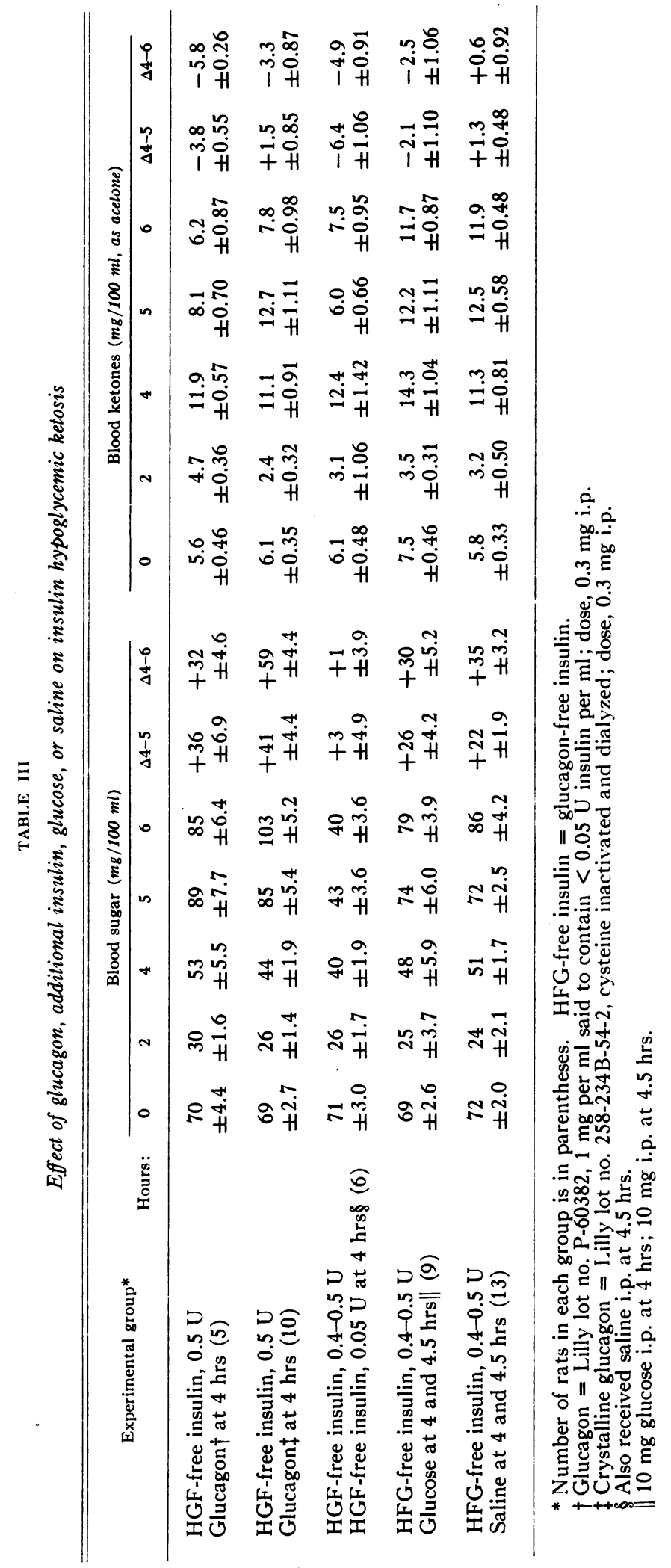


nemia remained unchanged. A rise in blood sugar from $53 \pm 1.3$ to $70 \pm 2.6 \mathrm{mg}$ per $100 \mathrm{ml}$ was surprising in view of the presumed depletion of liver glycogen in fasted hypophysectomizedadrenalectomized animals. The data obtained support the assumptions that cysteine treatment had inactivated any residual insulin present in the crystalline glucagon, and that at least $0.005 \mathrm{U}$ of insulin was present in the $0.3 \mathrm{mg}$ untreated glucagon injected.

The administration of a small dose of insulin $(0.05 \mathrm{U})$ at 4 hours led to a highly significant decline in ketones at 5 and 6 hours $(p<0.01)$. Hypoglycemia persisted throughout. This antiketogenic effect is comparable to that previously described during fasting ketosis (1). Glucose did not significantly alter the ketone levels. The dose of glucose was kept low to avoid hyperglycemia and subsequent endogenous insulin secretion. These results with insulin and insulin-contaminated glucagon strongly suggest that insulin deficiency during recovery from insulin hypoglycemia may play an important role in the development of the ketosis.

In most of the experiments ketonemia initially declined after administration of insulin, followed by a secondary rise at 4 and 6 hours. Both handling of rats and induction of hypoglycemia may result in release of epinephrine which conceivably might influence either the decline in ketonemia at 2 hours or the subsequent rise. Epinephrine administered intraperitoneally to intact 24-hour-fasted rats produced a significant rise in blood sugar at 1 and 2 hours $(p<0.01$ ) and a significant decline in ketonemia at 1 hour $(\mathrm{p}<0.01)$ (Table IV). Further study is necessary to determine whether this decline represents a direct action of epinephrine or is a consequence of induced insulin secretion.

When the above data were subjected to critical review, a number of questions was raised: Were adequate criteria used in determining the completeness of hypophysectomy? Could the alterations noted in glycemia and ketonemia be due to the trauma of handling and bleeding the rats rather than to the minute doses of insulin administered? Would adrenalectomized rats still develop ketosis if they did not receive injections of DCA?

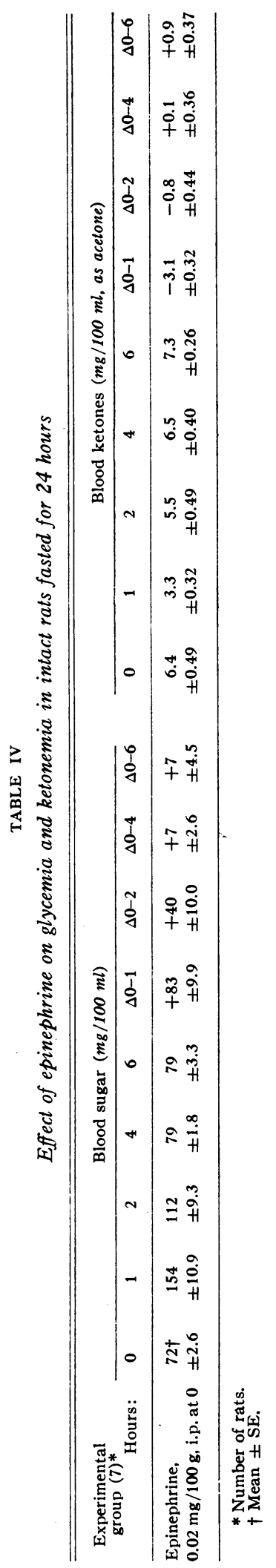


TABLE $v$

Insulin hypoglycemic ketosis in hypophysectomized rats *

\begin{tabular}{|c|c|c|c|c|c|c|c|c|c|c|c|c|c|c|}
\hline \multirow{2}{*}{$\begin{array}{l}\text { Experimental } \\
\text { group } \\
\text { Hours: }\end{array}$} & \multicolumn{7}{|c|}{ Blood sugar $(\mathrm{mg} / 100 \mathrm{ml})$} & \multicolumn{7}{|c|}{ Blood ketones ( $m g / 100 \mathrm{ml}$, as acetone) } \\
\hline & $\mathbf{0}$ & 2 & 4 & 6 & $\Delta 0-2$ & $\Delta 0-4$ & $\Delta 0-6$ & $\mathbf{0}$ & 2 & 4 & 6 & $\Delta 0-2$ & $\Delta 0-4$ & $\Delta 0-6$ \\
\hline $\begin{array}{l}\text { HYPOX } \dagger \\
\text { Controls }(7) \\
\text { Mean } \pm \mathrm{SE}\end{array}$ & $\begin{array}{l}67 \\
=3.0\end{array}$ & $\begin{array}{l}60 \\
\pm 2.3\end{array}$ & $\begin{array}{l}64 \\
\pm 1.6\end{array}$ & $\begin{array}{l}59 \\
\pm 3.4\end{array}$ & $\begin{array}{l}-7 \\
\pm 2.1\end{array}$ & $\begin{array}{l}-3 \\
\pm 2.2\end{array}$ & $\begin{array}{l}-8 \\
\pm 1.9\end{array}$ & $\begin{array}{c}3.0 \\
\pm 0.19\end{array}$ & $\begin{array}{c}3.8 \\
\pm 0.23\end{array}$ & $\begin{aligned} & 4.6 \\
\pm & 0.26\end{aligned}$ & $\begin{array}{c}4.1 \\
\pm 0.44\end{array}$ & $\begin{array}{l}+0.8 \\
\pm 0.21\end{array}$ & $\begin{array}{l}+1.6 \\
\pm 0.27\end{array}$ & $\begin{array}{l}+1.1 \\
\pm 0.37\end{array}$ \\
\hline $\begin{array}{l}\text { Intra-group } \\
\text { comparisons; } p=\end{array}$ & & & & & $<0.01$ & $>0.10$ & $<0.001$ & & & & & $<0.005$ & $<0.001$ & $<0.025$ \\
\hline $\begin{array}{l}\text { HYPOX } \\
\text { Insulin (8), } \\
0.017-0.020 \text { U } \\
\text { HGF-free insulin } \\
\text { i.p. at } 0\end{array}$ & $\begin{array}{l}66 \\
\pm\end{array}$ & $\begin{array}{l}27 \\
\pm 2.8\end{array}$ & $\begin{array}{l}31 \\
\pm 3.6\end{array}$ & $\begin{array}{l}38 \\
\pm 3.0\end{array}$ & $\begin{array}{l}-38 \\
\pm 4.1\end{array}$ & $\begin{array}{l}-35 \\
\pm 4.5\end{array}$ & $\begin{array}{l}-27 \\
\pm 3.4\end{array}$ & $\begin{array}{l}2.5 \\
\pm 0.16\end{array}$ & $\begin{array}{l}1.1 \\
\pm 0.17\end{array}$ & $\begin{array}{l}4.1 \\
\pm 0.25\end{array}$ & $\begin{array}{c}6.2 \\
\pm 0.16\end{array}$ & $\begin{array}{l}-1.4 \\
\pm 0.23\end{array}$ & $\begin{array}{l}+1.6 \\
\pm 0.30\end{array}$ & $\begin{array}{l}+3.7 \\
\pm 0.50\end{array}$ \\
\hline $\begin{array}{l}\text { Inter-group } \\
\text { comparisons; } p=\end{array}$ & $>0.5$ & $<0.001$ & $<0.001$ & $<0.001$ & & & & $\begin{array}{l}>0.05 \\
<0.10\end{array}$ & $<0.001$ & $\begin{array}{l}>0.10 \\
<0.20\end{array}$ & $<0.01$ & $<0.001$ & $>0.5$ & $<0.005$ \\
\hline
\end{tabular}

* Sprague-Dawley strain, 3.5-4.5 months post HYPOX (completeness of hypophysectomy verified histologically). Number of rats in each group is in parentheses.

t Same rats used for both control and insulin experiments (order of experiments varied).

In an attempt to answer these questions a final series of experiments was undertaken. $\mathrm{Hy}$ pophysectomized Sprague-Dawley rats were again obtained from The Endocrine Laboratories and were used 3.5 to 4.5 months after hypophysectomy. These rats also appeared to be completely hypophysectomized when judged by the criteria noted above. In addition, at autopsy serial sections of the sella turcica, sphenoid sinus, and adjacent pharyngeal mucosa failed to reveal any pituitary fragments.

The same hypophysectomized rats were used for both control and insulin hypoglycemia studies on different occasions. Some rats were studied as controls first while others received insulin initially. After a 2+-hour fast a blood specimen was obtained and either insulin diluted in saline or an equivalent volume of normal saline (usually 0.2 $\mathrm{ml}$ ) was injected intraperitoneally. The minute dose of insulin used, 0.017 to $0.020 \mathrm{U}$, was a critical factor, since a slightly larger dose, 0.025 to $0.037 \mathrm{U}$, almost uniformly caused convulsions, shock, or both. The rats tolerated the control experiments very well.

The results obtained are presented in Table V. When saline was administered there was little alteration in glycemia in contrast to the profound sustained hypoglycemia due to insulin. Some rise in ketonemia did occur during the control experiments, but insulin produced a decline in ketonemia at 2 hours and a greater degree of rise at 6 hours. The similarity to the pattern obtained in the previous studies is apparent. These results provide answers to the first two questions posed above, and support the conclusion that ketonemia may develop acutely in the rat in the absence of the pituitary gland.

It was not possible to answer the third question completely. Fasting, adrenalectomized rats not maintained on DCA tolerated insulin hypoglycemia poorly, even when they received saline intraperitoneally before the experiment in an attempt to maintain their circulatory status. Hypoglycemia uniformly resulted in shock, with or without convulsions, which if untreated resulted in death. However, the level of ketonemia in 19 adrenalectomized rats (maintained only on saline) subjected to a 24-hour fast was found to be 5.2 $\pm 0.31 \mathrm{mg}$ per $100 \mathrm{ml}$ (mean $\pm \mathrm{SE}$ ), only slightly lower than the fasting level found in intact Sprague-Dawley controls $(6.1 \pm 0.33)$ during the earlier studies. Therefore, the adrenal gland is not essential for the development of fasting ketosis. Mineralocorticoids of the adrenal cortex are important in the preservation of the circulation when adrenalectomized rats are subjected to insulin hypoglycemia. The unlikely possibility that mineralocorticoids exert a more specific effect on the rat's ability to develop ketosis acutely cannot be ruled out by these experiments.

\section{DISCUSSION}

The results of this study confirm and extend those obtained in man (10) and are similar to our findings in fasting ketosis (1), with one exception. Cortisone inhibited fasting ketosis but 
did not modify insulin hypoglycemic ketosis either in man or in the rat.

Endocrine and metabolic mechanisms in ketosis have been reviewed in several recent publications $(1,19-21)$ and will not be discussed in detail here. Neither the adrenal cortex nor the pituitary gland is essential for the rise in plasma free fatty acids (22) or for the development of ketosis during fasting (1). However, in the absence of those glands, the magnitude of the ketosis provoked by a given degree of hypoglycemia was less than in normals (1). Normal rats had maximal ketone levels and minimal blood sugar levels on the second day of fasting, and thereafter both levels returned toward the fed state. This pattern of recovery could be reproduced in hypophysectomized rats by small daily doses of cortisone, implying a permissive role of the adrenal cortex in the augmentation of gluconeogenesis. Fasting ketosis in hypophysectomized-adrenalectomized rats was promptly abolished by a minute dose of insulin, suggesting that suppression of insulin secretion is an important factor in fasting ketosis.

A similar general pattern occurs in insulin hypoglycemic ketosis, an accelerated form of fasting ketosis. Insulin hypoglycemia evokes the secretion of epinephrine (23), glucagon (24), and of ACTH and adrenocortical steroids (25). Since these hormones have been implicated in adipokinesis and ketosis, the endocrine-deficient rat should have difficulty in developing ketosis promptly. Our results failed to confirm this prediction, agreeing with the previous findings in fasting ketosis (1).

The initial decline in ketonemia in response to insulin could be due to diminished ketogenesis, increased ketolysis, or a combination of both. Early studies reported that neither insulin nor carbohydrate affected the rate of disappearance of infused ketone bodies (26) and suggested that utilization of carbohydrate diminished ketosis by decreasing ketogenesis. This concept has derived additional support from more recent demonstrations of such direct effects of insulin or carbohydrate utilization, or both, as : enhanced uptake of glucose by the liver (27); decreased ketogenesis by surviving liver slices (28); diminished net splanchnic ketone production (10); decrease in the net release of free fatty acids from adipose tissue both in vivo and in vitro $(29,30)$; and diminished oxidation of administered albuminbound palmitate (31). Oxidation of fatty acids to ketones virtually halts and lipogenesis is enhanced.

Recently the possibility of a direct effect of insulin on ketolysis has been reconsidered. McPherson, Werk, Myers and Engel studied the effects of glucose and insulin on net splanchnic ketone production in man during an infusion of sodium octanoate (10). Arterial blood ketone levels were lower when insulin and glucose were infused than with glucose alone, despite comparable net splanchnic ketone production. This suggested a direct peripheral effect of insulin on ketone body utilization. In addition, insulin has a direct in vitro effect upon the uptake of acetoacetate by rat muscle (32).

The possibility that epinephrine caused the initial decline in ketonemia was also considered. The decline was less marked in adrenodemedullated rats, and administration of epinephrine decreased fasting ketonemia in the intact rat. However, an initial decline in ketonemia did occur in totally adrenalectomized rats. The sparse literature on epinephrine and ketosis in the rat is confusing, since both augmentation and suppression have been reported.

The rise in ketonemia following hypoglycemia can be explained more readily. Accelerated carbohydrate utilization is opposed by epinephrine, adrenal cortical steroids via ACTH, and possibly by growth hormone or other pituitary hormones. These factors also facilitate mobilization of fatty acids from adipose tissue $(33,34)$ to the glycogen-depleted liver where they are incompletely oxidized, resulting in ketosis. The inverse relationship between liver glycogen levels and ketosis (35) explains the ability of cortisone pretreatment to suppress fasting but no postinsulin hypoglycemic ketosis. Other factors may play a role, since neither cortisone nor glucose will prevent the ketogenic response to oxycel corticotropin in the rat (36).

While endocrine glands may facilitate ketosis, they are not essential for ketosis following insulin hypoglycemia. It is not clear whether they influence the magnitude of the ketonemia, as in fasting ketosis (1). The endocrine-deficient animals exhibited lower initial levels of blood sugar than 
intact controls and were exquisitely sensitive to insulin. It was not possible to induce comparable degrees of hypoglycemia when parameters such as absolute or percentage decline in glycemia and duration of hypoglycemia were considered. Another major difficulty rests in our ignorance of the actual rates of both ketogenesis and ketolysis in either intact or endocrine-deficient animals. In the hypophysectomized rat triiodothyronine increased insulin hypoglycemic ketosis and thyroxine restored the depressed rate of ketogenesis in surviving liver slices from hypophysectomized rats (12). However, triiodothyronine did not augment fasting ketosis in hypophysectomized rats (1).

Suppression of endogenous insulin secretion by hypoglycemia undoubtedly plays an important role in the genesis of postinsulin hypoglycemic ketosis just as it does in fasting ketosis (1). The abrupt decline in post-hypoglycemic ketonemia in response to a minute second dose of insulin suggests that an absolute deficiency of endogenous insulin may be more important in the early development of ketonemia than are insulin antagonists. This belief is reinforced by the similar pattern of ketonemia exhibited by the hypophysectomized rat, which is deficient in insulin antagonists, and by direct studies on the pancreas, which demonstrate diminished content and secretion of endogenous insulin after insulin hypoglycemia $(13,14)$.

The present studies do not support the contradictory reports that glucagon stimulates (16) or suppresses (17) ketosis but rather agree with the view that glucagon has no influence on ketonemia (37). Some of the conflicting data may be due to antiketogenic amounts of insulin in the preparations of glucagon or endogenous insulin secretion in response to glucagon-induced hyperglycemia. Randle has also emphasized the necessity of inactivating residual insulin in both crystalline and amorphous glucagon preparations (38), and insulin contamination has been demonstrated by immunoassay (39).

Insulin hypoglycemia triggers the secretion of adrenal cortical steroids but these hormones are not essential for ketosis. Although DCA was necessary for adrenalectomized rats to tolerate insulin hypoglycemia, it seems unlikely that min- eralocorticoids of the adrenal play a specific role in ketosis. DCA is not essential for fasting ketosis in the adrenalectomized rat. Surviving liver slices from adrenalectomized rats produce ketone bodies at a rate equal to or greater than normal $(12,40)$. The role of the adrenal gland in the mobilization of fat from peripheral depots is not entirely clear. Earlier reports and some recent studies have demonstrated lipolysis and mobilization to be impaired in adrenalectomized animals both in vivo and in vitro (41). However, others have found that fat mobilization was maintained $(42,43)$, and the utilization of free fatty acids by a variety of tissues was actually increased (43). The latter observation suggests that the failure of various stimuli to produce hyperlipemia or fatty liver in adrenalectomized rats may be due to accelerated utilization of fatty acids rather than to impaired adipokinesis (43). Furthermore, administration of large amounts of glucocorticoids before and during insulin hypoglycemia does not affect the magnitude of ketonemia. The present studies did not determine whether large amounts of glucocorticoids accelerate the rate of recovery from insulin hypoglycemic ketonemia. While glucocorticoids are generally considered to have antiketogenic activity, this effect may be due to stimulation of endogenous insulin secretion. In this regard it is of interest that rats must be exposed to glucocorticoids for at least 24 hours before they exhibit an increased capacity to secrete insulin (44). Furthermore, cortisone actually enhances ketosis in the totally pancreatectomized-hypophysectomized rat unless insulin is also administered (45). Since the postinsulin hypoglycemic rat is insulin-deficient, glucocorticoids might be unable to exert their antiketogenic effect. Another possible explanation is that glucocorticoids may play a "permissive role" (46) in exerting an antiketogenic effect after insulin hypoglycemia. since they appear to act in that fashion in fasting ketosis (1). The present experiments do not provide sufficient data to answer that question. A prolongation of the experiments beyond 8 hours in intact and adrenalectomized rats, and in adrenalectomized rats maintained on a "permissive" dose of cortisone might provide the necessary information and complete the link between insulin hypoglycemic ketosis and the ketosis of prolonged fasting. 


\section{SUMMARY AND CONCLUSIONS}

The role of the hypophysis and other endocrine glands in ketonemia during insulin hypoglycemia was studied in rats fasted for 24 hours. In intact rats insulin caused an initial decline in ketonemia followed by a rise 4 and 6 hours after insulin. Although previous administration of cortisone preserved abundant liver glycogen and suppressed fasting ketosis. it did not prevent postinsulin hypoglycemic ketosis. Liver glycogen was depleted in the latter instance. Insulin hypoglycemic ketosis also occurred in adrenalectomized, adrenodemedullated, hypophysectomized, and hypophysectomized-adrenalectomized rats. Adrenalectomized rats did not tolerate insulin hypoglycemia unless maintained on DCA. DCA was not necessary for fasting ketosis. Exact quantitative comparisons were inconclusive because of differing degrees of hypoglycemia and ignorance of the rates of ketogenesis and ketolysis. Treatment of hypophysectomized rats with triiodothyronine seemed to enhance the degree of ketonemia.

Crystalline glucagon, treated to inactivate residual insulin, had no effect on insulin hypoglycemic ketosis while additional insulin decreased ketonemia. Epinephrine caused a rapid temporary decline in fasting ketosis.

The hypophysis, adrenal medulla, and glucocorticoids of the adrenal cortex are not essential for the development of ketosis after insulin hypoglycemia. Suppression of endogenous insulin secretion probably plays an important role in the genesis of the ketosis.

\section{ACKNOWLEDGMENTS}

Dr. Thomas Albertson, Miss Ruth Westcott and Mrs. Sara Chambers provided technical assistance during part of these studies.

We are grateful to Dr. Elmer Alpert, Merck Sharpe \& Dohme, Rahway, N. J. (cortisone); Dr. Otto K. Behrens, Lilly Research Laboratories, Indianapolis, Ind. (glucagon-free insulin and glucagon); Dr. Robert Gaunt, Ciba Pharmaceutical Co., Summit, N. J. (deoxycorticosterone acetate) ; and to Dr. Arthur E. Heming, Smith, Kline \& French Research Laboratories, Philadelphia, Pa. (triiodothyronine) for generous supplies of the hormone preparations used in these studies.

\section{REFERENCES}

1. Amatruda, T. T. Jr., and Engel, F. L. The role of the endocrine glands in ketosis. I. The ketosis of fasting. Yale J. Biol. Med. 1959, 31, 303.
2. Peters, J. P., and Van Slyke, D. D. Quantitative Clinical Chemistry. Vol. I. Interpretations, 2nd ed. Baltimore, Williams \& Wilkins, 1946, p. 442.

3. Somogyi, M. Exacerbation of diabetes by excess insulin action. Amer. J. Med. 1959, 26, 169.

4. Heming, A. E., and Holtkamp, D. E. Calorigenic and antigoitrogenic actions of L-triiodothyronine and L-thyroxine in thyroidectomized and intact rats. Proc. Soc. exp. Biol. (N. Y.) 1953, 83, 875.

5. Somogyi, M. Determination of blood sugar. J. biol. Chem. 1945, 160, 69.

6. Werk, E. E., Jr., McPherson, H. T., Hamrick, L. W., Jr., Myers, J. D., and Engel, F. L. Studies on ketone metabolism in man. I. A method for the quantitative estimation of splanchnic ketone production. J. clin. Invest. 1955, 34, 1256.

7. Engel, F. L., and Hewson, K. Fatty acid and ketone metabolism during hemorrhage and shock in the rat. Proc. Soc. exp. Biol. (N. Y.) 1953, 83, 608.

8. Good, C. A., Kramer, H., and Somogyi, M. The determination of glycogen. J. biol. Chem. 1933, $100,485$.

9. Scott, J. L., Jr., and Engel, F. L. The influence of the adrenal cortex and cold stress on fasting ketosis in the rat. Endocrinology 1953, 53, 410.

10. McPherson, H. T., Werk, E. E., Jr., Myers, J. D., and Engel, F. L. Studies on ketone metabolism in man. II. The effect of glucose, insulin, cortisone and hypoglycemia on splanchnic ketone production. J. clin. Invest. 1958, 37, 1379.

11. Engel, M. G., and Engel, F. L. Fasting ketosis in the adrenalectomized and cortisone-treated rat. Endocrinology 1954, 55, 593.

12. Bondy, P. K., and Wilhelmi, A. E. Effect of hormones upon the production of ketone bodies by rat liver slices. J. biol. Chem. 1950, 186, 245.

13. Best, C. H., and Haist, R. E. The effect of insulin administration on the insulin content of the pancreas. J. Physiol. (Lond.) 1941, 100, 142.

14. Zunz, E., and La Barre, J. L'Hypoglycémie insulinique diminue-t-elle la production d'insuline par le pancréas? C. R. Soc. Biol. (Paris) 1927, 96, 1045.

15. Foa, P. P. The control of the secretory activity of the islets of Langerhans. (Internal secretions of the pancreas.) Ciba Found. Coll. Endocr. 1956, 9, 55.

16. Haugaard, E. S., and Haugaard, N. The effect of hyperglycemic-glycogenolytic factor on fat metabolism of liver. J. biol. Chem. 1954, 206, 641.

17. Kalant, N. Metabolic effects of the pancreatic hyperglycemic factor. Proc. Soc. exp. Biol. (N. Y.) 1954, 86, 617.

18. Beigelman, P. M., Goetz, F. C., Antoniades, H. N., and Thorn, G. W. Insulin-like activity of human plasma constituents: I. Description and evaluation of biological assay for insulin-like activity. Metabolism 1956, 5, 35.

19. Engel, F. L. The influence of the endocrine glands on fatty acid and ketone body metabolism. Arch. intern. Med. 1957, 100, 18. 
20. Campbell, J., and Best, C. H. Symposium on diabetes: physiologic aspects of ketosis. Metabolism 1956, 5, 95.

21. Krebs, H. Biochemical aspects of ketosis. Proc. roy. Soc Med. 1960, 53, 71.

22. Barros Barreto, H. P., and Recant, L. Failure of hypophysectomy, adrenalectomy or thyroidectomy to affect response of non-esterified fatty acids to fasting. Proc. Soc. exp. Biol. (N. Y.) 1960, 104, 627.

23. von Euler, U. S., and Luft, R. Effect of insulin on urinary excretion of adrenalin and noradrenalin: Studies in 10 healthy subjects and in 6 cases of acromegaly. Metabolism 1952, 1, 528.

24. Unger, R. H., Eisenstraut, A. M., McCall, M. S., and Madison, L. L. The hormonal role of endogenous glucagon in blood: Glucose homeostasis as demonstrated by a specific immunoassay (abstract). J. clin. Invest. 1960, 39, 1036.

25. Bliss, E. L., Migeon, C. J., Eik-Nes, K., Sandberg, A. A., and Samuels, L. T. The effects of insulin histamine, bacterial pyrogen, and the antabuse-alcohol reaction upon the levels of 17 -hydroxycorticosteroids in the peripheral blood of man. Metabolism 1954, 3, 493.

26. Mirsky, I. A., and Broh-Kahn, R. H. The influence of dextrose administration on the utilization of B-hydroxybutyric acid by the normal and eviscerated rabbit. Amer. J. Physiol. 1937, 119, 734.

27. Madison, L. L., Combes, B., Adams, R., and Strickland, W. The physiological significance of the secretion of endogenous insulin into the portal circulation. III. Evidence for a direct immediate effect of insulin on the balance of glucose across the liver. J. clin. Invest. 1960, 39, 507.

28. Stadie, W. C., Zapp, J. A., Jr., and Lukens, F. D. W. The effect of insulin upon the ketone metabolism of normal and diabetic cats. J. biol. Chem. 1940, $132,423$.

29. Bierman, E. L., Schwartz, I. L., and Dole, V. P. Action of insulin on release of fatty acids from tissue stores. Amer. J. Physiol. 1957, 191, 359.

30. Gordon, R. S., Jr., and Cherkes, A. Production of unesterified fatty acids from isolated rat adipose tissue incubated in vitro. Proc. Soc. exp. Biol. (N. Y.) 1958, 97, 150.

31. McCalla, C., Gates, H. S., Jr., and Gordon, R. S., Jr. $\mathrm{C}^{14} \mathrm{O}_{2}$ excretion after the intravenous administra- tion of albumin-bound palmitate-1- $\mathrm{C}^{14}$ to intact rats. Arch. Biochem. 1957, 71, 346.

32. Beatty, C. H., Peterson, R. D., Bocek, R. M., and West, E. S. Acetoacetate and glucose uptake by diaphragm and skeletal muscle from control and diabetic rats. J. biol. Chem. 1959, 234, 11.

33. Fredrickson, D. S., and Gordon, R. S., Jr. Transport of fatty acids. Physiol. Rev. 1958, 38, 585.

34. Engel, F. L., and White, J. E., Jr. Some hormonal influences on fat mobilization from adipose tissue. Amer. J. clin. Nutr. 1960, 8, 691.

35. Mirsky, I. A. The source of the blood acetone resulting from the administration of the ketogenic principle of the anterior hypophysis. Amer. J. Physiol. 1936, 115, 424.

36. Engel, M. G., and Engel, F. L. Influence of cortisone on the ketogenic response to oxycel corticotropin. Endocrinology 1958, 62, 75.

37. Bondy, P. K., and Cardillo, L. R. The effect of glucagon on carbohydrate metabolism in normal human beings. J. clin. Invest. 1956, 35, 494.

38. Randle, P. J. The effect of glucagon preparations on the uptake of glucose by isolated rat diaphragm. J. Endocr. 1958, 17, 396.

39. Yalow, R. S., and Berson, S. B. Immunoassay of insulin content of crystalline glucagon preparations. Proc. Soc. exp. Biol. (N. Y.) 1961, 107, 148.

40. Perry, W. F., and Bowen, H. F. In itro metabolism of fatty acids by adipose and liver tissue of the adrenalectomized rat. Amer. J. Physiol. 1957, $189,433$.

41. Wertheimer, E., and Shafrir, E. Influence of hormones on adipose tissue as a center of tat metabolism. Recent Progr. Hormone Res. 1960, 16, 467.

42. Levy, A. C., and Ramey, E. R. The effect of adrenal steroids on peripheral fat mobilization in the rat. Endocrinology 1959, 64, 586.

43. Perry, W. F., and Bowen, H. F. The in vitro utilization and production of non-esterified fatty acids by adrenalectomized rats. Canad. J. Biochem. 1961, 39, 1061.

44. Albertson, T., and Engel, F. L. Unpublished data.

45. Scow, R. O., Chernick, S. S., and Guarco, B. A. Ketogenic action of pituitary and adrenal hormones in pancreatectomized rats. Diabetes 1959, 8, 132.

46. Ingel, D. J. Permissibility of hormone action; a review. Acta endocr. (Kbh.) 1954, 17. 172. 